\title{
SEISMIC PERFORMANCE OF A PRECAST REINFORCED CONCRETE WALL WITH CUT-OUT OPENING RETROFITTED USING CARBON FIBRE STRIPS
}

\author{
M. Fofiu $^{\text {a, }}$, A. Bindean ${ }^{\text {a }}$, V. Stoian ${ }^{\text {a }}$ \\ a "Politehnica" University of Timisoara, Faculty of Civil Engineering, Traian Lelescu 2, Timisoara 300223, Timis, Romania, \\ *e-mail: andrei.bindean@student.upt.ro
}

Received: 13.03.2015 / Accepted: 31.03.2015 / Revised: 28.04.2015 / Available online: 31.05.2015

DOI: 10.1515/jaes-2015-0002

KEY WORDS: Retrofit, Experimental Test, CFRP, Carbon Strips, Precast, Reinforced Concrete, Seismic Behaviour

\begin{abstract}
:
The Precast Reinforced Concrete Wall Panel (PRCWP) presented in this paper is part of an experimental study regarding the seismic performance of precast reinforced concrete wall panels, strengthening strategies and investigation on the weakening induced by modifying the opening in these elements due to architectural demands, change of function of buildings or other reasons. The element presented is 1:1.2 scale typical Reinforced Concrete Wall Panel with a window opening used in Romania, in which the opening was changed to a door opening due to comfort considerations. The specimen was subjected to cyclic loading with the lateral loads being applied in displacement control of $0.1 \%$ drift ratio. This simulates the shear behaviour of the element. After testing the unstrengthen element we proceed to retrofit it using Carbon Fibre Strips anchored with Carbon Fibre Mash. The purpose of the paper is to present the strengthening strategy and restore the initial load bearing capacity of the element or even increase it. The experimental results of strengthen and unstrengthen specimens will be presented.
\end{abstract}

\section{INTRODUCTION}

The present experimental programme was designed to investigate the seismic behaviour of Precast Reinforced Concrete Wall Panel (PRCWP) in order to evaluate the effects of cut-out openings in the elements and to determine the efficiency of the retrofitting methods using Carbon Fibre Reinforced Polymers (CFRP).

The purpose of this paper is to determine the seismic performance of one PRCWP with a door (E1) cut-out opening made from a PRCWP with an initial small widow opening (L1), situated at the ground floor of a five story building, were most of this interventions are made and were both the gravity and seismic capacity demands are maximum, to describe the retrofitting strategy by means of CFRP using Externally Bonded Reinforcement (EBR) and to compare the maximum load bearing capacity from the weakened reinforced concrete wall panel to that of the strengthened specimen.

Due to the fact that in the past 50 years in Romania the vast majority of new apartment buildings were made using Precast
Reinforced Concrete Large Panels (PRCLP) as structural system, slender walls have a lower ultimate strength (Robinson, 2013), (Saheb, 1989, 1990), (Doh, 2005), (Ganesan, 2013) and that a staggering large portion of this buildings were made over 30 years ago, it is necessary to study the behaviour of this panels under seismic loading.

In Romania owners of apartments in these old buildings started to feel the need of a better space distribution, so they proceeded to cut-out openings or enlarge the existing ones in these large reinforced concrete panels, to create entrances at the base floor of the buildings for commercial spaces.

\section{MATERIAL AND METHODS}

\subsection{Experimental Programme}

\subsubsection{Test Specimen}

The element presented in this paper is PRCWP used in the typical five storeys residential buildings from 1970 to 1990 in

\footnotetext{
* Corresponding author.
} 
Romania. In figure 1 it is presented the panels distribution for the building with the indicative 770-81, one of many designs used in these buildings (Demeter 2011).
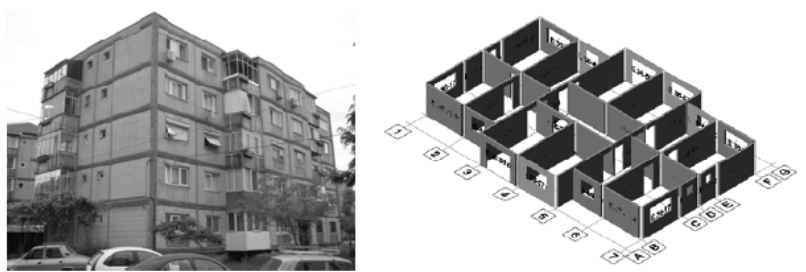

Figure 1. Project type 770-81
All features of the experimental test specimen like: dimensions, reinforcement details and material properties are taken from an existing building. The element had to be scaled down by a factor of 1:1.2 because the laboratory in which the tests were conducted had a limited height and the testing gear peaked at $1000 \mathrm{KN}$.

Figure 2 depicts the reinforcement distribution in the element and it can be seen that the top coupling beam is the most reinforced while in the bottom part below the initial window opening the reinforcement had been cut. The tested specimen had the following dimensions: $2750 \mathrm{~mm}$ length, $2150 \mathrm{~mm}$ height and $100 \mathrm{~mm}$ thickness, while at each end there was a heavily reinforced $\mathrm{T}$ shaped boundary element which prevented the out of plane displacement, in figure 3 can be seen the reinforcement and dimensions of these two elements.

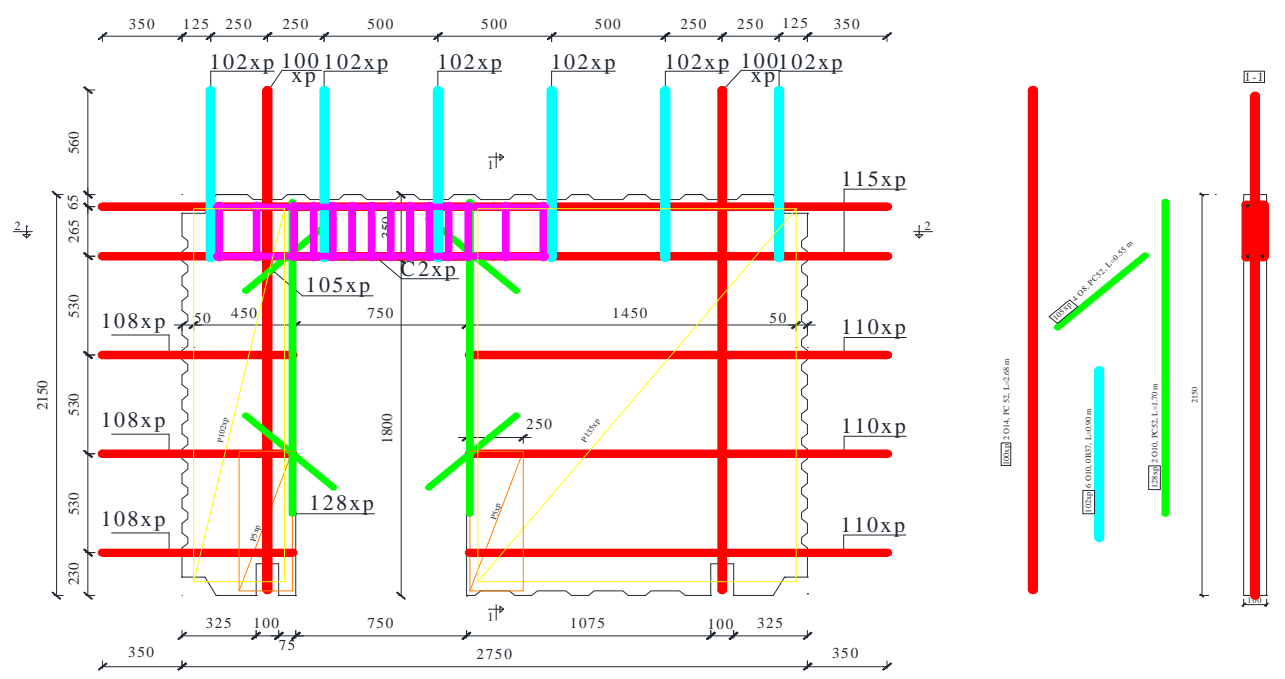

$\mathrm{C} 2$

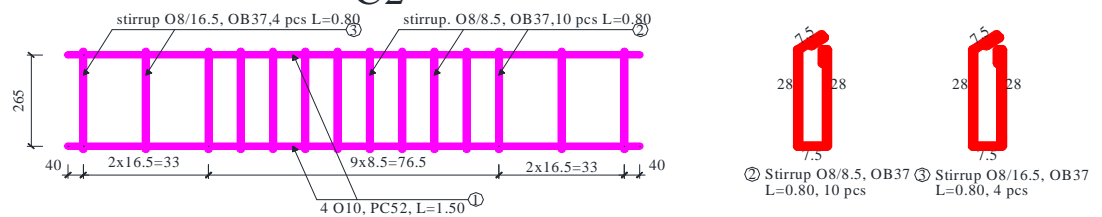




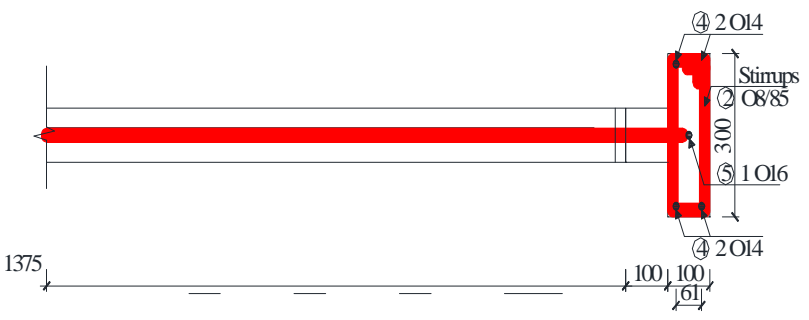

Figure 3. Reinforcement for the T boundary elements

The concrete ordered for the element was $\mathrm{C} 16 / 20$, however when the standard tests on $150 \mathrm{~mm}$ cubes were conducted it was observed that the concrete delivered satisfied the conditions for c25/30 concrete having a compressive strength of $29.03 \mathrm{~N} / \mathrm{mm}^{2}$.

\subsubsection{Test Set-Up}

The test set-up was designed to reproduce the seismic behaviour of the specimen by subjecting the tested element to pseudoconstant axial in-plane reversed cyclic lateral forces. Two composite steel-concrete beams were used, one as force transmitter on top of the element and one as foundation underneath the element. The lateral (seismic) forces were induced by two hydraulic jacks supported by laterals reaction frames as seen in Figure 4. In order to counter the rocking effect of the element when tested, two hydraulic jacks were each inducing a constant $150 \mathrm{kN}$ vertical force through steel rollers to enable the in-plane displacement and were increased in displacement control by $100 \mathrm{kN}$ for every $1 \mathrm{~mm}$ increase in vertical movement of the element.
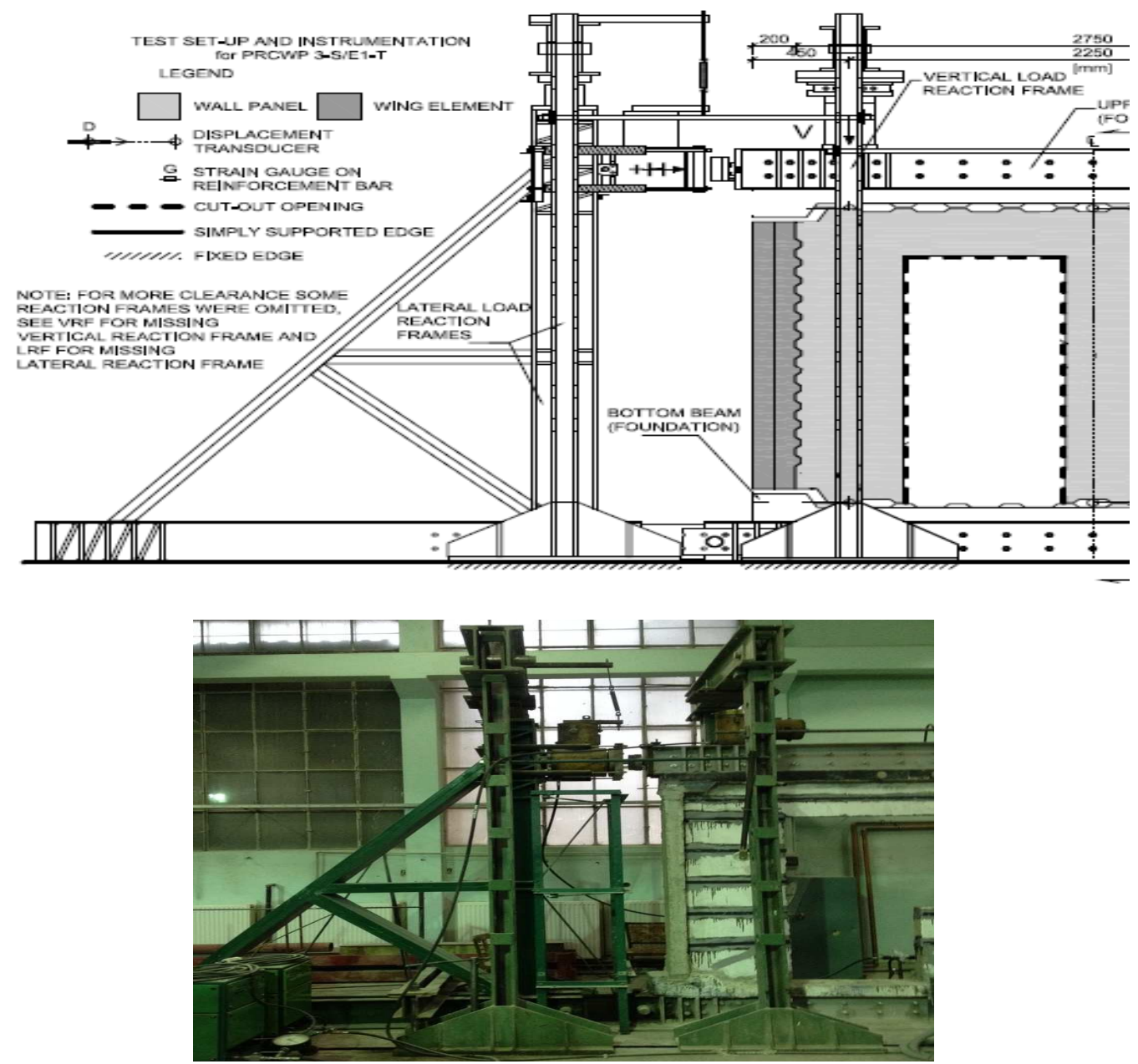

Figure 4. Test set-up

Both the initial and the retrofitted specimen were subjected to the same loading procedure, the lateral (seismic) loading history was defined in terms of displacement control of 0,1 drift ratio. Since the height of the element was $2150 \mathrm{~mm}$ the displacement control increments were $0.1 \%(2.15 \mathrm{~mm}), 0.2 \%(4.3 \mathrm{~mm}), 0.3 \%$ $(6.45 \mathrm{~mm})$ etc. as seen in figure 5 . For each displacement levels two loading cycles were done until the failure. The criteria were considered fulfilled when a $20 \%$ decrease of load bearing capacity was obtained from one cycle to another. For the measuring of the displacement, a number of 6 displacement transducers were used for both tests. 


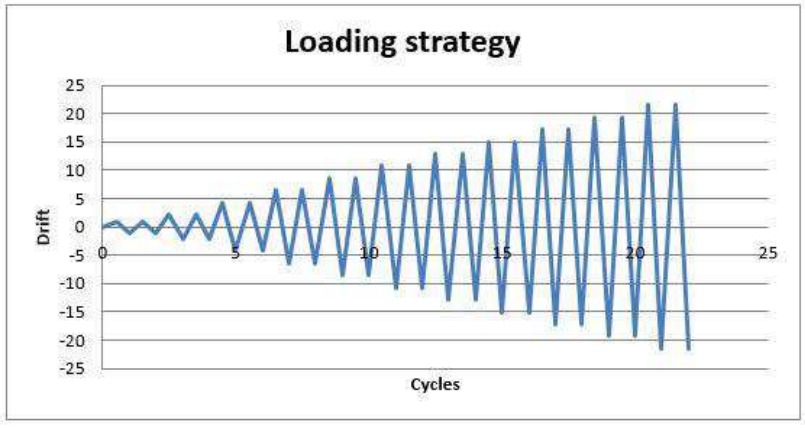

Figure 5. Loading Strategy

\subsection{Strengthening Strategy}

The principles of the strengthening strategy were based on the behaviour and failure observed during the testing of the unstrengthen specimen. The successful application of FRP to strengthen solid concrete walls has been achieved in several studies (Demeter, 2011), (Mohammed, 2013), (Li, 2010), (Li, 2013), (Dan, 2012), (Todut, 2015), (Antoniades, 2005), (Maadawy, 2009), (Enochsson, 2007), (Florut, 2014). The retrofitting was performed by means of Carbon Fibre Reinforced Polymers (CFRP) using Externally Bonded Reinforcement (EBR) technique for both increasing the shear strength and to stich the cracks. The properties of the materials used in this procedure are given in Table 1.

\begin{tabular}{|l|l|r|r|r|r|}
\hline No. & Name & $\mathrm{mm}$ & $\mathrm{g} / \mathrm{cm}^{3}$ & $\begin{array}{r}\text { Thickness } \\
\text { N/ming }\end{array}$ & Density \\
strength & Viscosity \\
\hline 1 & $\begin{array}{l}\text { Carbon } \\
\text { strips }\end{array}$ & 1.4 & $\begin{array}{r}0.0016 \\
1\end{array}$ & 3100 & - \\
\hline 2 & $\begin{array}{l}\text { Epoxy } \\
\text { resin }\end{array}$ & - & 1.06 & 40 & 7000 \\
\hline 3 & $\begin{array}{l}\text { Carbon } \\
\text { mesh }\end{array}$ & 0.166 & 1.8 & 4830 & - \\
\hline
\end{tabular}

Table 1. Material Properties

The first step of the retrofitting procedure was to prepare the concrete surface on the areas were the carbon fibre strips would be placed by grinding the surface in order to remove all prominent imperfections, debris of mortar and irregularities of the surface.

Then drilling the holes were the anchorage CFRP mesh would be introduced and finally removing the dust particles by blowing the surface with compressed air.

The second step was to cut the carbon fibre strips and anchorages to the specified dimensions which were as follow: $30 \mathrm{~mm}$ wide and $1.4 \mathrm{~mm}$ thick for the carbon strips and $300 \mathrm{~mm}$ in length and $100 \mathrm{~mm}$ in width for the anchorages. Figure 7A depicts the position of the carbon fibre strips and the CFRP anchorages, while figure $7 \mathrm{~B}$ depicts the strengthened element. A total of one $2950 \mathrm{~mm}, 41600 \mathrm{~mm}$ and $4600 \mathrm{~mm}$ long strips were used for each side of the wall, the sides being symmetrically reinforced. For the anchorage part a total of 23 CFRP anchorages were used and are shown in figure 6 .

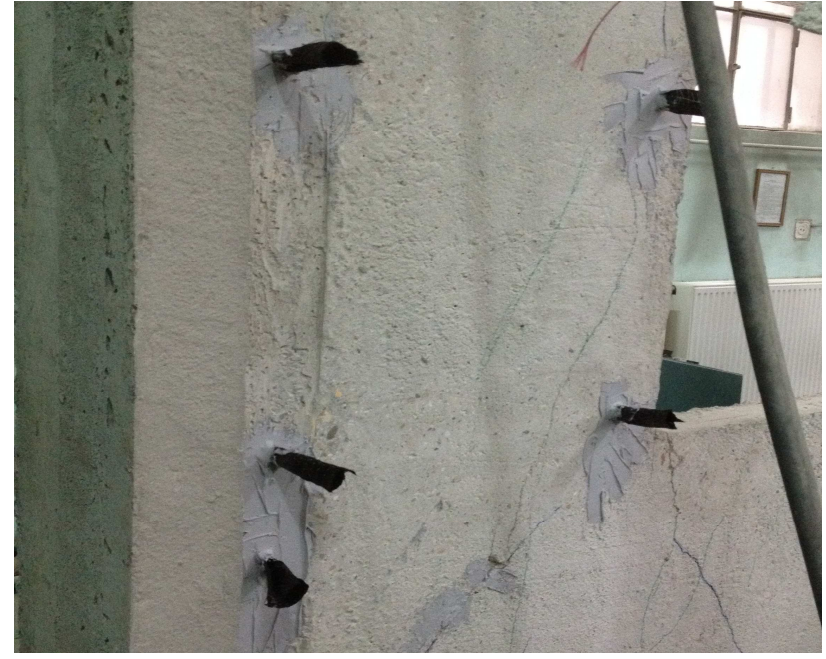

Figure 6. CFRP Anchors
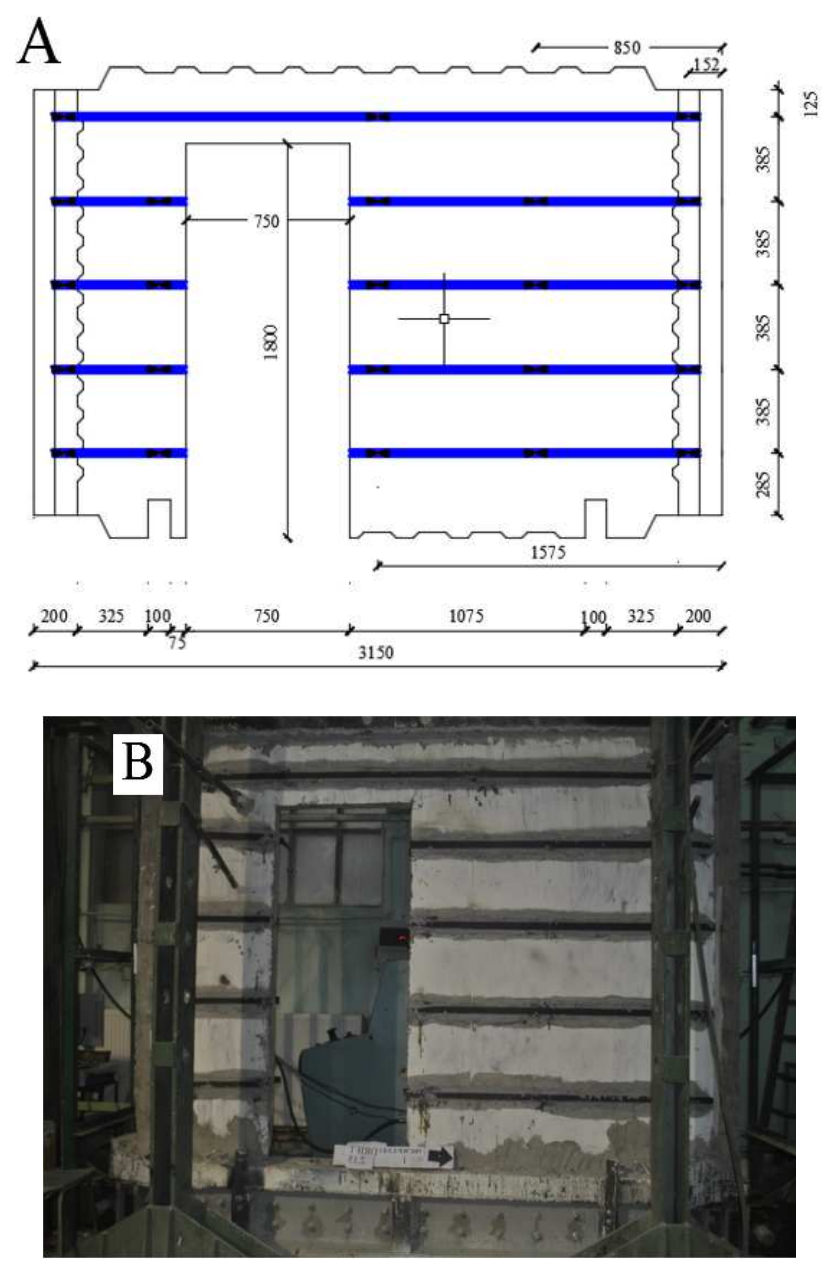

Figure 7. Strengthened Element

\section{BEHAVIOUR AND RESULTS}

\subsection{Unstrengthen Element}

The specimen had a ductile behaviour, as expected, with the main cracks appearing in the top coupling beam. The element 
failed due to excessive crushing of concrete in the lower part as seen in the figures 10,11 . The maximum load was obtained on negative drift, meaning when we applied the force from right to left. The maximum seismic load bearing capacity of the unstrengthen element was $502 \mathrm{kN}$ at $8.6 \mathrm{~mm}(0,4 \%)$ negative drift level, but the failure occurred on positive drift level, the element losing more than $20 \%$ of its load bearing capacity at $12,9 \mathrm{~mm}$ reaching only $220 \mathrm{kN}$ while in the previous cycle at $10,75 \mathrm{~mm}$ had a maximum force of $355 \mathrm{kN}$ (figure 8).

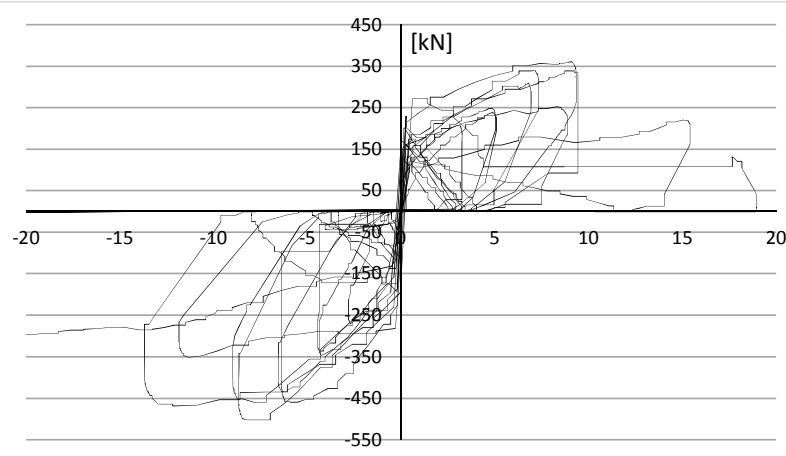

Figure 8. Seismic Force-Displacement Diagram

The maximum vertical forces were $395 \mathrm{kN}$ respectively $215 \mathrm{kN}$ as seen in the diagrams below (figure 9).

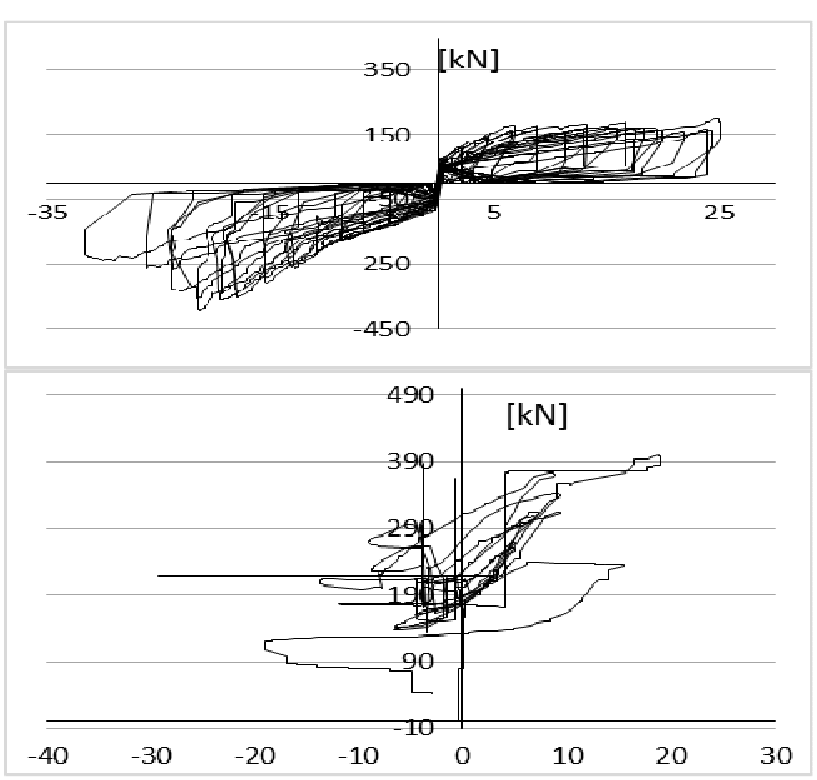

Figure 9. Vertical Force-Displacement Diagrams
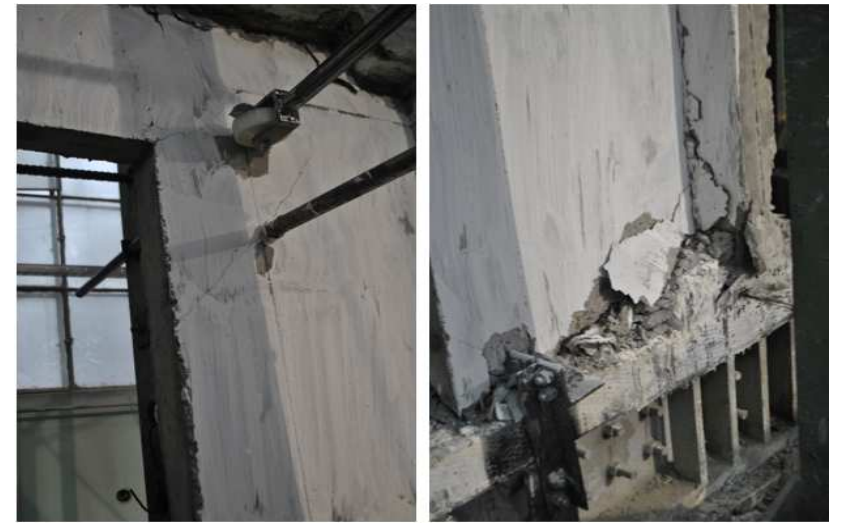

Figure 10. Unstrengthen Element Failure Details
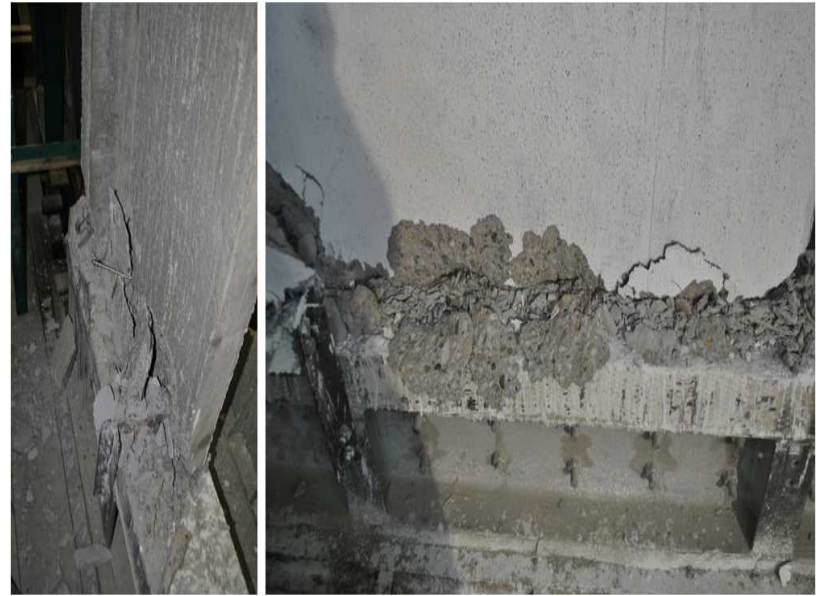

Figure 11. Unstrengthen Element Failure Details

\subsection{Retrofitted Element}

After the retrofitting procedure was finished and the epoxy resins had enough time to dry out, we did the same test on the element. Failure occurred due to extreme crushing of concrete in the top corners of the opening and de-bonding of the retrofitting procedure as seen in the detailed failure figures. The retrofitted specimen had a maximum seismic load bearing capacity of $395 \mathrm{kN}$ at a drift ratio of $21,5 \mathrm{~mm}(10 \%)$ negative drift level (figure 12) and the element lost more than $20 \%$ of its load bearing capacity at $25,8 \mathrm{~mm}(12 \%)$ drift level with a maximum force of $264 \mathrm{kN}$. The maximum vertical forces were $345 \mathrm{kN}$ respectively $190 \mathrm{kN}$ (figure 13). 


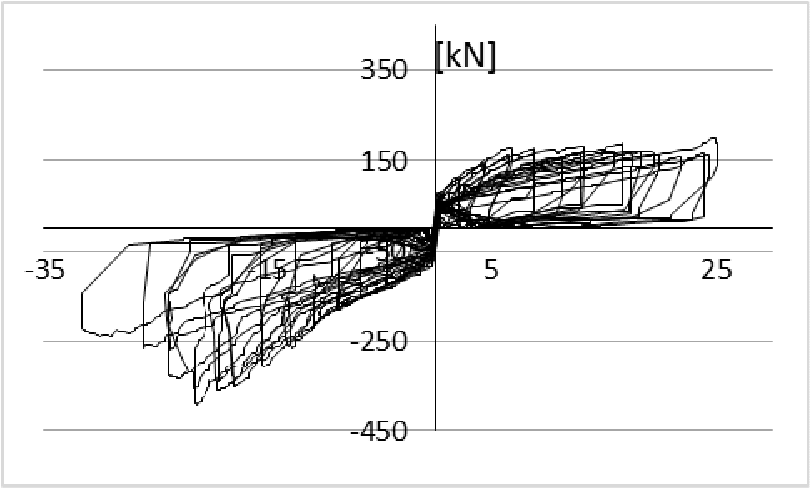

Figure 12. Seismic Force-Displacement Diagram

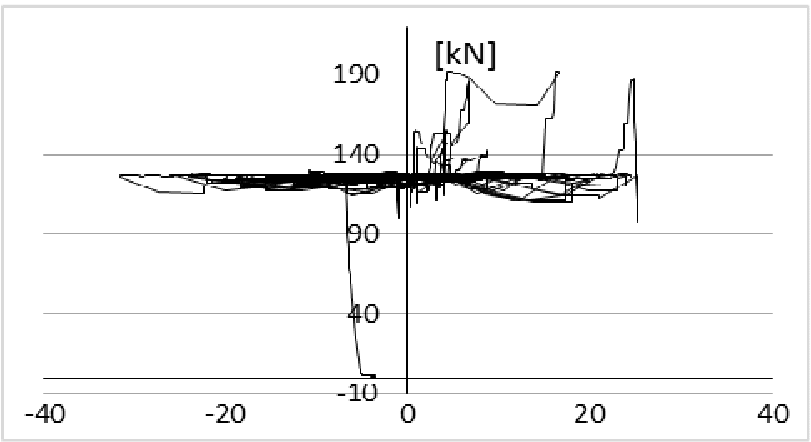

Figure 13. Vertical Force-Displacement Diagram

The first cracks started to appear in the top left corner at drift level of $4,3 \mathrm{~mm}(0,2 \%)$, while the cracks in the right corner appeared at $6,45 \mathrm{~mm}(0.3 \%)$. These cracks continued to open and extend during the experimental test until they eventually the element lost its bearing capacity (figure 14).

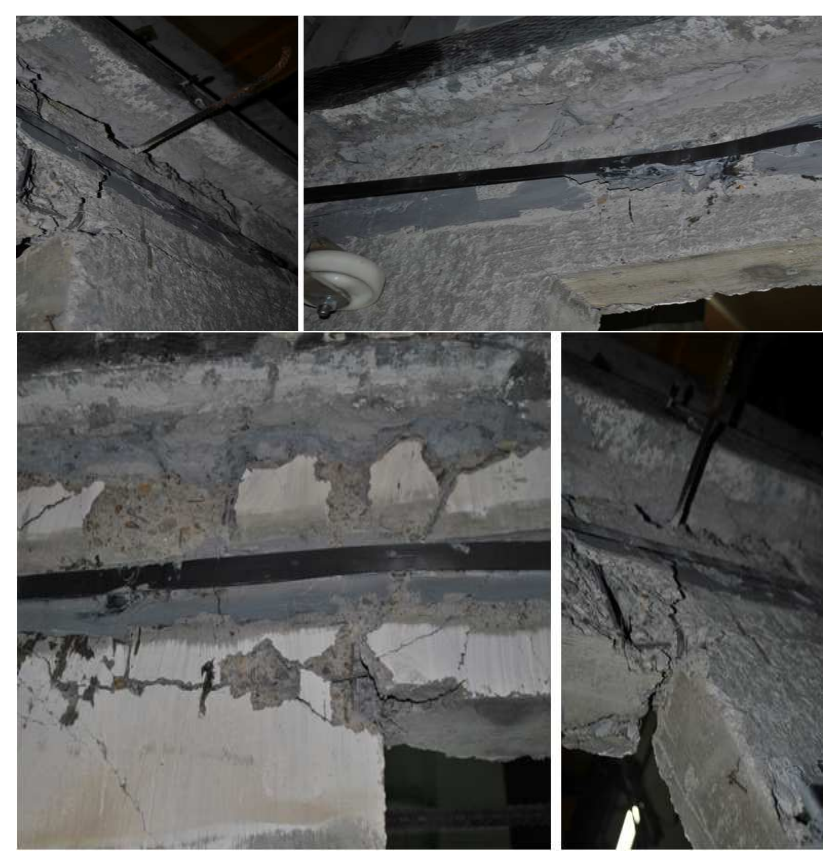

Figure 14. Retrofitted Element Failure Details

\section{COMPARISON AND CONCLUSIONS}

The purpose of the experimental test was to observe the behaviour of the element during seismic actions and to see if the applied retrofitting procedure can restore the load bearing capacity of the tested specimen.

Comparing the results from the two experimental tests it can be seen that most of the initial load bearing capacity was restored. Due to the fact that the concrete in the initial test was severely destroyed it was difficult to repair the PRCWP without compromising its stability or costing to much. From Figure 15 it can be seen that the retrofitted element had $78 \%$ of the initial element load bearing capacity, but had an increased drift level with $100 \%$ making the element much ductile. Figure 16 depicts the difference between the two tests maximum drift ratio.

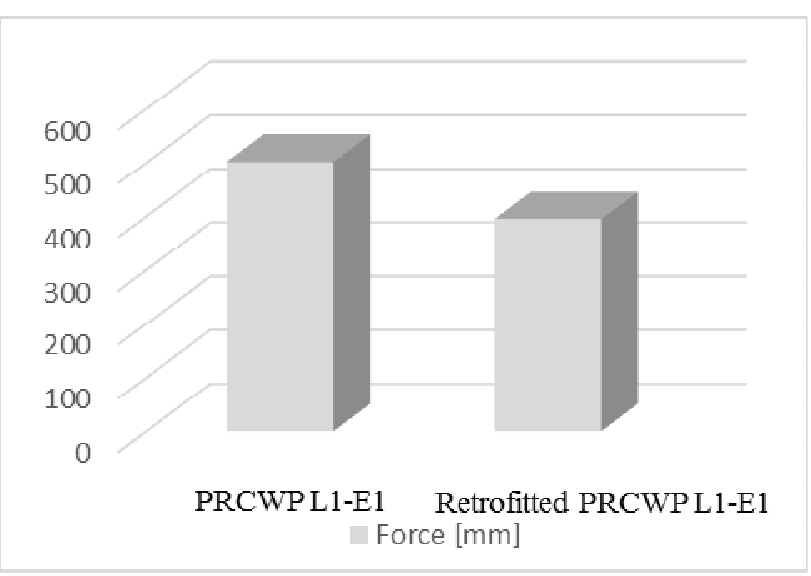

Figure 15. Maximum Force Comparison

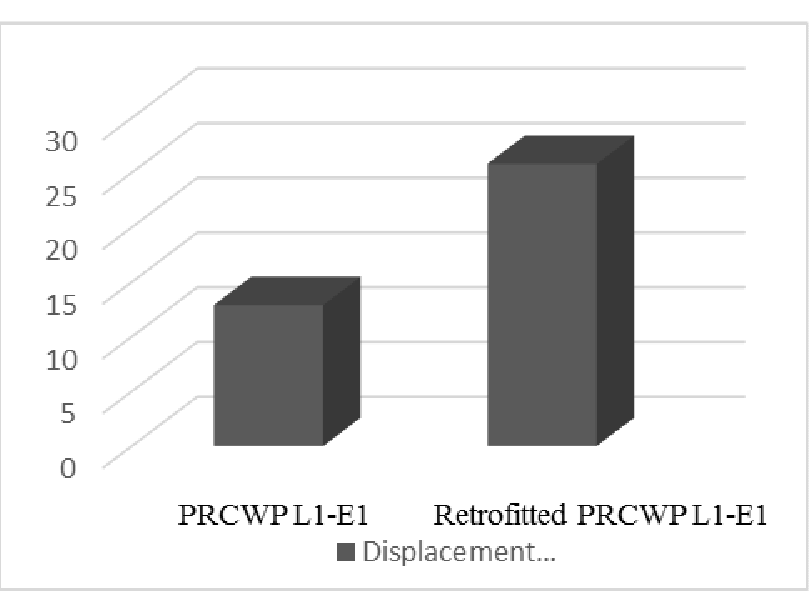

Figure 16. Maximum Drift Comparison 


\section{REFERENCES}

ACI 440.2R-08, 2008. Guide for the design and construction of externally bonded FRP systems for strengthening concrete structures, American Concrete Institute, Farmington Hills.

Antoniades K, Salonikios T, Kappos A., 2005. Tests on seismically damaged reinforced concrete walls repaired and strengthened using fiber-reinforced polymers. J Compos Constr 9:236-46

Dan D., 2012. Experimental tests on seismically damaged composite steel concrete walls retrofitted with CFRP composites. Eng Struct, 45:338-48.

El Maaddawy T, Sherif S, El Maaddawy T, Sherif S., 2009. FRP composites for shear strengthening of reinforced concrete deep beams with openings. Compos Struct 89:60-9.

Enochsson O, Lundqvist J, Taljsten B, Rusinowski P, Olofsson T., 2007. CFRP strengthened openings in two-way concrete slabs - an experimental and numerical study. Constr Build Mater, 21:810-26.

Florut S-C, Sas G, Popescu C, Stoian V., 2014. Tests on reinforced concrete slabs with cut-out openings strengthened with fibre-reinforced polymers. Compos Part B - Eng, 66:48493.

Ganesan, N., Abraham, R., Beena, P.R., Thomas, A., 2014. Behaviour of ultra high performance concrete wall panels under two-way in-lane loading. International Journal of Structural Engineering 5(3), pp.262-278

Ganesan N, Indira PV, Santhakumar A., 2013. Prediction of ultimate strength of reinforced geopolymer concrete wall panels in one-way action. Constr Build Mater. 48:91-7.

Li B, Lim C., 2010. Tests on seismically damaged reinforced concrete structural walls repaired using fiber-reinforced polymers. J Compos Constr, 14: 597-608.

Li B, Qian K., 2013. Retrofitting earthquake-damaged RC structural walls with openings by externally bonded FRP strips and sheets. J Compos Constr, 17:259-70.

Mohammed B, Ean LW, Malek MA., 2013. One way RC wall panels with openings strengthened with CFRP. Constr Build Mater, 40:575-83.

Robinson G, Palmeri A, Austin S., 2013. Design methodologies for one way spanning eccentrically loaded minimally or centrally reinforced pre-cast RC panels. Eng Struct, 56:194556.

Seddon AE., 1956. The strength of concrete walls under axial and eccentric loads. In: Andrew RP, editor. Symposium on the strength of concrete structures. London, UK: Cement and Concrete Association; p. 445-86.

Saheb SM, Desayi P., 1989. Ultimate strength of RC wall panels in one-way in-plane action. J Struct Eng-Asce, 115:2617-30.
Todut C, Dan D, Stoian V., 2015. Numerical and experimental investigation on seismically damaged reinforced concrete wall panels retrofitted with FRP composites. Compos Struct, 119:648-65.

Demeter I., 2011. Seismic retrofit of precast $R C$ walls by externally bonded CFRP composites. Romania: $\mathrm{PhD}$ Thesis, Politehnica University of Timisoara.

\section{ACKNOWLEDGEMENTS}

1. This paper was partially supported by the strategic grant POSDRU/159/1.5/S/134378 (2014) of the Ministry of National Education, Romania, co-financed by the European Social Fund - Investing in People, within the Sectoral Operational Programme Human Resources Development 2007-2013.

2. This paper is supported by the Sectoral Operational Programme Human Resources Development POSDRU/ 159/1.5/S/137516 financed from the European Social Fund and by the Romanian Government.

3. MAPEI Company by representative Mr. Cristi Cartas.

4. This paper is supported by the Sectorial Operational Programme Human Resources Development (SOP HRD), ID134378 financed from the European Social Fund and by the Romanian Government. 
